\title{
Montage: Expanding the Concept of Informing through Cinematic Concepts
}

\author{
Emad Moaddab \\ Kamalolmolk University, Noshahr, Mazandaran, Iran \\ emad.moaddab@gmail.com
}

\begin{abstract}
In his "Theses on the Philosophy of History", Walter Benjamin suggests that all cultural treasures "owe their existence not only to the efforts of the great minds and talents who have created them, but also to the anonymous toil of their contemporaries. There is no document of civilization which is not at the same time a document of barbarism". The most obvious and prominent examples of cultural treasures in Benjamin's discourses can be found in monumental architectural works, and history has shown that rulers have really been interested in such splendor stone statements. Benjamin's discourse challenges a dominant idea that seeks to give an ambitious image of these architectural works with the purpose of confirming and endorsing a splendid cultural past so that it can give shape to an integrated and arbitrary cultural geography. This theoretical study, which has been conducted using library resources, employing the discourse and method of "cinematic thinking", attempts to review the role of these monumental architectural works in establishing and shaping national cultural geography. This process is an effort to open boundaries of theorization in area of art and architecture, with the help of ideas that moving cinematic images leave in place.
\end{abstract}

Keywords: cinematic thinking, monumental architectural works, cultural documents, montage, cultural imaginary geography.

\section{Introduction}

Interdisciplinary studies refers to "the process of communication, interaction, and integration of knowledge, concepts, experiences, and specialties of two or several scientific disciplines which is conducted with purpose of comprehensive recognition, dynamic understanding, and scientific analysis of real problems, subjects, and phenomena" (Khorsandi Tasko, 2008, p. 36). Interdisciplinary studies create a space between participating disciplines and focus on overlapping areas between disciplines. In these studies, relations are quite relative, and participating parties can

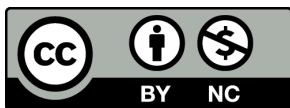

This article has been copyrighted by the Informing Science Institute on behalf of its authors. We license it to you under a Creative Commons AttributionNonCommercial 4.0 International License. When you copy and redistribute this paper in full or in part, you need to provide proper attribution to it to ensure that others can later locate this work (and to ensure that others do not accuse you of plagiarism). You may (and we encourage you to) adapt, remix, transform, and build upon the material for any non-commercial purposes. This license does not permit you to use this material for commercial purposes. benefit from hypotheses and fundamentals of involved perspectives disciplines proportionately. Interdisciplinary studies, by expanding boundaries of knowledge, enable examination of different phenomena with various perspectives obtained from different disciplines and by opening traditional boundaries of fields to one another, expand potentials of each of participating areas. The more interdisciplinary studies can cross barriers and walls that separate disciplines, the more dynamic and creative interdisciplinary interactions are realized. In order to build a common ground in interdisciplinary stud- 
ies, the following techniques have been proposed (Repko, Newell, \& Szostak, 2011):

1- Redefinition: Semantic explanation \& adaptation of terms and hypotheses

2- Extension: Extension of a new idea or territory

3- Organization: Explaining implicit commonalities between areas and describing the commonalities between them

4- Transformation: Observing differences

Some theorists believe that in interdisciplinary studies, boundaries and territories of each of disciplines remain unchanged and that in the process of adjacency and fellowship, each of participating disciplines keep their independence. Another group suggests that interdisciplinary approaches can challenge initial hypotheses of involved branches, and as a result of cooperation and participation between disciplines, new hypotheses might emerge in each of the disciplines. This is the stance advanced by the Informing Science Institute. Therefore, the interdisciplinary approach, by exposing silent and hidden aspects, enables crossing and violating rigid formats and established boundaries (Khorsandi Tasko, 2008). Through the extension of interdisciplinary studies, according to Klein, "treatment of knowledge as a foundation or a linear structure, has been replaced by terms such as network and web" (as cited by Khorshidi \& Pishgahi, 2012, p. 5). Concerning the nature of interdisciplinary studies, a reference could be made to the illuminating analysis of Gilles Deleuze about the concept of "and". For Deleuze, "and" shapes a space for interweaving and amalgamation of two territories. "And" creates an interaction, exchange, and dialogue between the participant parties. This dialogue is a freedom from whatever establishes conversation parties in their existence. Deleuze points to the difference between "and" and "relation", emphasizing the creative and innovative performance of "and" (as cited by Tawa, 2010, p. 12-13). "And" in the relationship between two independent areas and territories, creates a site and ground where capacities and potentials of these areas are resonated and echoed. Each of participating realms in this interaction exposes the other to their inner weird, silent, forgotten, and suppressed characteristics, deterritorializing itself in this process.

\section{Montage Methodology in Interdisciplinary Studies}

Some believe that postmodern thinking essentially finds its meaning by rejecting concepts such as integration, totality, continuity, constancy, and resistance and by moving to such concepts as discontinuity, destabilization, and fragmentation. Thinkers such as Foucault, Derrida, Lyotard, and Deleuze challenge concepts such as totality and integration and emphasize that any attempt to represent a phenomenon as an integrated and stable image, an image that seeks to represent totality and coherence of that phenomenon, will be an abortive effort. Also, any integrated and coherent representation will be concurrent with the concept of suppression and dominance. According to theorists, in the postmodern era, through indices such as lack of eternal trust in the concept of progress, decadence of metanarratives, and divergence of discourses in methodological terms in the area of study, a challenging situation has formed.

Montage is the principle governing organization of visual and audio elements. It is a process by which the film maker, by cutting pieces and reestablishing new joints between them, creates nascent relations, adjacency, and meanings. In the process of montage, two pieces of film are put together and inevitably establish a new idea, a new quality that rises from adjacency of those two. Adjacency of two shots that might have no relation from the spatially or temporally aspects, induces shock in the audience, and encourages them to interact in the process of building meaning (Andrew, 1976/2010). George Marcus, a contemporary post-structural anthropologist, believes that montage, by challenging single-line representations of phenomena, is a methodology by which contradicting and spatial/temporal/narrative inconsistent adjacencies of the contemporary time can be understood: "a critical intellectual montage becomes, in the contemporary idiom, a deconstruction in action, and its aim is to decompose categories that construct basic ideological 
concepts of common sense such as the individual, gender, or class" (Marcus, 1995, p. 46). Referring to the "cinematic basis" of contemporary human's experience, Markus stresses that montage is essentially based on multi-perspective components and discontinuity, and "lends technique to the desire to break with existing rhetorical conventions and narrative modes through exposing their artificiality and arbitrariness" (p. 37). In an obvious contradiction with stable and constant characteristics of popular academic methodologies, montage methodology basically rests on qualities such as extension, discontinuity, explosion, and instability (Denzin \& Lincon, 2011, p. 5). This explosive power of montage, in removing monopolistic space of each of these areas and breaking the boundaries between these territories (Emberley, 2002), can act as an effective approach, being helpful in movement to deterritorialization between artistic fields and creation of new theories.

\section{Primal Nature \& Wild Montage Thinking}

There are various routes through which cinematic configurations can challenge traditional methods of thinking. Experience of cinematic thinking refers to how cinematic form can prepare and provide modern thinking styles. In a rhizomatic cinematic space, each point and space can join other points and spaces free from each limitation, disjoining hierarchical structures and form a hierarchy-free space. Through the rhizomatic nature of these images, audience's thinking can constantly establish relative and fluid liaisons between these images. This power of cinema in looking through nonhuman and multiple perspectives induces a completely new type of thinking in the audience (Deleuze, 2005; Philips, 2008, p. 1-9). According to Deleuze (2005), cinema theory is not about cinema and films, but rather concept-creation styles and creation of ideas specific to this medium. It is about the concept that cinema develops, methods by which cinema creates new links between various areas and fields (Stam, 2000/2010, p. 307).

The works and ideas of Sergei Eisenstein (1991) are one of the most important and elementary examples of this cinematic thinking. The great filmmaker and theorist of the Soviet cinema was the prominent and a full scale example of cinematic thinking. Eisenstein refers to fragmentary, explosive, and detaching effects of this montage thinking, emphasizing that this type of thinking leads to creation of new concepts and perspectives. Using a montage style, Eisenstein makes use of any source for giving his theories (from Lenin and Stalin to products of Walt Disney, from the architecture of Gothic and Baroque to paintings of El Greco and Picasso, from popular fictions to writings of Gogol, Freud, and Hegel, etc.), and by putting together these irrelevant and disparate segments, shaped the heterotopic geography of his thinking. Influenced by Hegel's ideas regarding the relationship between image and concept, he believed that each picture can as such be a source of thinking. However, while Hegel (as Cited by Nesbet, 2003, p. 17-18) belittled imagebased philosophy and never considered it comparable with philosophers' serious tradition of thinking, for Eisenstein cinematic thinking with images served as a modern and nascent type of thinking that was propounded as a serious alternative in countering the tradition of philosophizing. He sought roots of his artifacts concerning image-oriented cinematic thinking in the oldest allegories of thinking and Plato's famous Allegory of the Cave, but unlike the Platonist view, which gave warning regarding the dangers and threats of the cave's images for philosophy, Eisenstein tried to unveil some unique capacities of this type of thinking. Instead of praising concentration meditation in traditional philosophy, montage thinking values the transition between levels of values and diverse thinking by sudden jumps, fractures, and route changes, avoiding philosophic meditation, and admiring being on surface (Nesbet, 2003). This transition from traditional boundaries of philosophizing allowed Eisenstein to fearlessly put some pornographic folklore fictions beside profound philosophic concepts of thinkers such as Hegel and Freud. Escape of this type of thinking from traditional classifications and binaries of philosophy, such as transcendental/banal, deep/superficial, intellectual/popular, etc., gave a dynamic, fluid, and changing nature to this type of thinking. 
For Eisenstein, the meaning of montage was not just limited to preparation and organization of cinematic elements, but also involved motivating mental and physical cells of the audience as well. Using cinema-cave capacities for motions and flux of images, he proposed an aggressive model for stimulating and disturbing minds of the audience. Eisenstein's montage is a concept mixed with physical and sensual effects which completely opposes mind-oriented Cartesian views and seeks to create an inner echo in the audience that developed as a result of combination and amalgamation of all mental, physical and emotional abilities. By pointing to the physical, bodily, aggressive, and sexual nature of contemporary thinking, Eisenstein sought to achieve a kind of sensuous thought via his cinematic montage (Nesbet, 2003, p. 17, 112). Montage is derived from a French verb which implies an animal relation. By referring to this point, Eisenstein stresses the animal root of this type of thinking and mentions it with phrases such as thinking wildly, primal thinking, and montage thinking. The primal and terrifying nature of this thinking was its advantage and major priority over concepts such as civilized and educated, which, by destroying union, continuity, and integration, allowed ruptures and fragments to manifest (Nesbit, 2003, pp. 114-132) (Figure 1).
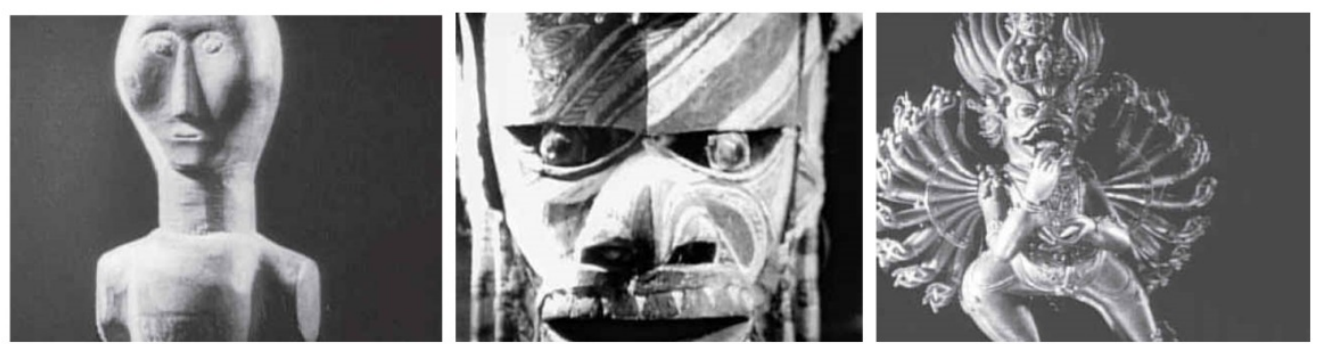

Figure 1. Primal nature of montage $\&$ its wild thinking according to Eisenstein (source: Nesbet, 2003, p. 84).

Eisenstein was not alone in his discourse in support of this type of image-oriented cinematic philosophy. Another important theorist who tried to reconfigure philosophy by involving images and the relationship between diverse images was the great thinker of Frankfurt School, Walter Benjamin (1936/2011): "The painting invites the spectator to contemplation; before it the spectator can abandon himself to his associations. Before the movie frame he cannot do so. No sooner has his eye grasped a scene than it is already changed. It cannot be arrested" (pp. 62-63). While photographic images and paintings invite the audience to thinking and concentration and meditation, like Eisenstein Benjamin believed that the fluid, dynamic, and transitive nature of moving cinematic images act as a driving motor that create a type of thinking based on flux, motion, and diverse thought in the audience. In the process of watching film, flux of images on the screen, substitution and ending each image with other images leads to transition from ideas, violation, and mental hiatus. The viewers cannot keep their power and dominance against the sequence of images, and the fluidity and dynamism of images create a flow and movement in their mental and sensuous contexts. According to Benjamin and Eisenstein, vagueness of formed ideas was a point that was very interesting.

Eisenstein believed that in his montage cinema, an interwoven link develops between the audience and the landscape drawn in the film (including spatial-audio-sensuous, etc.) and through dynamics and transition of these landscapes, the audience can move across different discrete landscapes, and might have different spatial experiences. In this regard, it could be argued that thinking with cinematic images is a type of journey across territories and lands. Cinematic thinking, "is a kind of movement, like dancing or shaking a fist. Like any physical movement, thinking, too, depends for any forward motion on the dialectical incorporation of recoil" (Nesbet, 2003, p. 210). 


\section{Architecture as an Informer: Monumental Architectural Works as Documents of Greatness \& Cultural Integration}

Throughout history, once policy makers and rulers took over power, they embarked on building palaces, social foci, and urban projects which represented power and showed the legitimacy of their newly established government. In the recent decade many instances of these practices can be seen. Moscow Renovation Project (1935) in the former Soviet Union and in Stalin's government manifested a pattern of urban expansion to represent the splendor and strength of the communist government to people under their rule as well as the rest of the world. This plan would turn Moscow into a city whose big boulevards and gigantic buildings would compete with the splendor of classic Rome. In Italy, Mussolini compared himself with the big emperors of Ancient Rome such as Tsar and Augustine and sought to renovate architectural works of that pompous era. Mussolini's fascistic government, by discovering utility of Rome emperorship and its architectural manifestations as a representational backup to strengthen his government (Lampugnani, 1985/2011, p. 174), sought to send a visuospatial propaganda across the country to impress the people by his newly established power. How Mussolini had transformed monuments of the Roman Empire into cultural-political symbols of his fascistic government had also drawn praises of Adolf Hitler in Germany. Hitler, like Mussolini, always praised the classic Rome, a land whose splendid monuments reflected power and greatness of its political government. Roman Coliseums, Baths of Caracalla, and the Pantheon had transformed into inspirational sources attached to the ruling government in Hitler's era. The enthusiasm of Hitler, who personally monitored a lot of architectural and urban projects in Berlin, the Roman Empire's use of architecture and urbanization for political goals and establishing the power of the government, made him order his favorite architect, Albert Speer, to make Berlin a rival for Ancient Rome in terms of urban design and architecture (Figure 2).

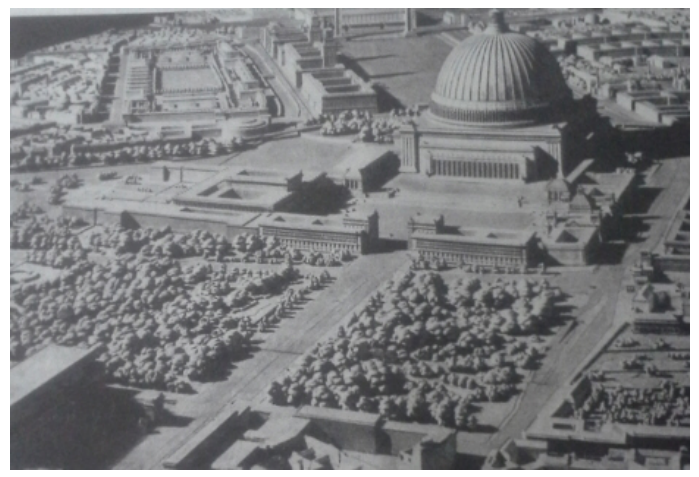

Figure 2. Speer's design for Berlin's Great Hall, reminiscent of the splendor of the Ancient Rome (source: Lampugnani, 1985/2011, p. 173).

Therefore, colossal architectural works in Nazi Germany under Hitler transformed into an inseparable part of political power. In his understanding of the impact of architecture in establishing the ruling power, Hitler was influenced by ideas of the Austrian architect and theorist, Gottfried Semper (Taylor, 1974). Semper believed that monumental architectural buildings play a significant role in dominance and governance over the masses and, therefore, can be made an important tool in the hands of the ruling power for establishing the position of the ruler. As buildings such as the Parthenon and Pantheon had been able to explain the biggest manifestation of greatness of Greek and Roman civilizations, Hitler sought famous architects who were able to establish an ideal, eternal, and immortal image of his government using architecture. He had stated that architecture presents magnificent, effective, and stable statements from each era in the mold of phrases 
and "the word in stone" (Taylor, 1974, p. 30) and each splendid period has presented itself using its buildings. By looking at architectural works of a civilization, it could be understood whether that civilization was subject to fall and decadence or apogee and progress.

By being aware of the propagandizing role of monuments within the society, Hitler believed that architecture with its messages can teach patriotic aspirations to the masses (Jaskot, 2002). From this point of view, many of the urban buildings and projects in the period of Nazi government can be evaluated based on the principle of manifestation and representation of patriotic morale. Hitler believed that architecture can institutionalize cultural enormity and power of union and consistency of the great German nation and reflect it to the world. In his speech in Socialist National Party Congress, he asserted:

"These structures have been built to reinforce this power ... because it is these that will politically contribute to unity and strength of our people. For German people, these structures will turn into an element of proud feeling of attachment to one another... Psychologically, these structures, alongside an unlimited self-confidence, will create this feeling as well: feeling of being German.” (Lampugnani, 1985/2011, p. 173)

Despite the suppressive policy of Nazi German in arrest and deportation of artists, Hitler paid a special attention to architects, and this was mostly due to his personal belief in the effective role of architecture in society. In My Memories, he introduces himself as a potential architect who gave up his favorite dream job for the sake of his patriotic mission: "If Germany had not lost the World War, I would not certainly become a politician, but rather an important architect, someone like Michelangelo" (Lampugnani, 1985/2011, p. 178). For Hitler, architecture was considered the most transcendental form of art that specifically has the capability to subconsciously exert the highest direct influence over the masses (Taylor, 1974, p. 31). Therefore, it could be said that suppression of individual identity and reflection of governing ideology in Nazi government would be shaped by architectural formidable and splendid but silent statements. In the article Fascinating Fascism, Suzanne Sontag (2002) addresses this practice of fascism in massing people's groups and transforming people to things and joining people and things around the unparalleled governing power (Figure 3). Also, explanation of Walter Benjamin of fascism as "aestheticization of politics" has an obvious inference to this function of art and architecture in line with the goals of the governing power in Nazi German government as well as Italian fascist government (Koepnick, 1999).

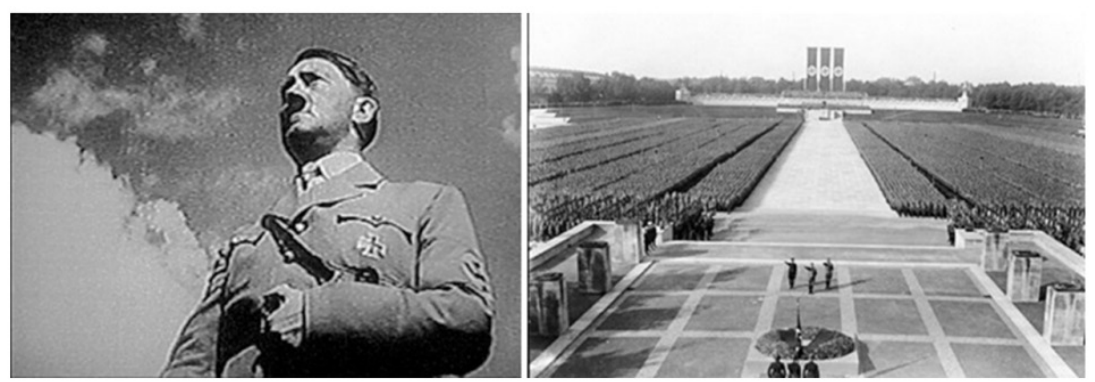

Figure 3. Fascism's aestheticization in shots from the movie Triumph of the Will by Leni Riefenstahl, showing a congregation of the Nazi Party

\section{Montage in Architecture: Documents of Civilization and Barbarism}

Looking at images of the chapter of Tower of Babel in the film Metropolis (1927) by Fritz Lang (Lang et al, 1989) and attempting to make connection between these images created a weird and 
inconsistent style of thinking in the audience. Transition and flux of these images have the capability to challenge their audience regarding architectural monuments and civilizing works. The chapter of Tower of Babel starts with these images (Figure 4) and phrases (among writings):

Let's together build a tower whose height will reach the stars. And on top of this tower we'll write: "the world and its god is great and man is great"... but minds that imagined the Tower of Babel, were unable to build it, it was very difficult. Therefore, they hired hands to build the tower... and the hands that built the Tower of Babel had no awareness of the dream of the minds that had imagined the tower.

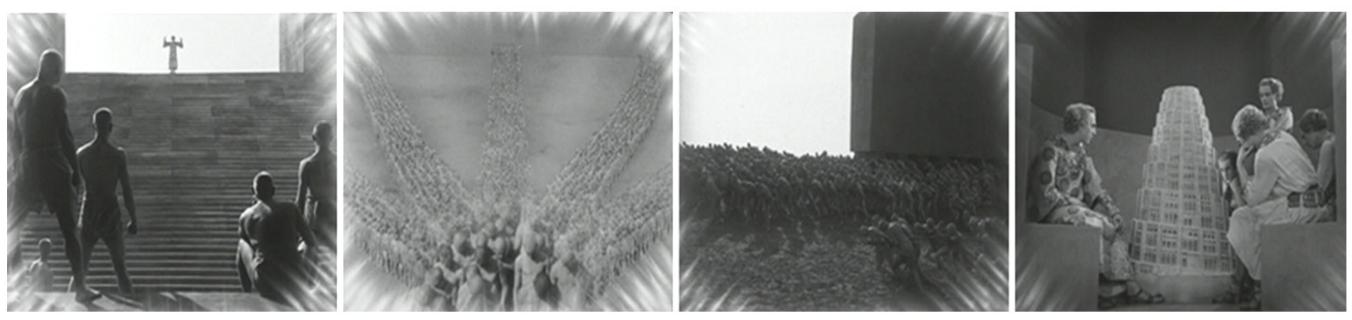

Figure 4 - Shots from the chapter of Tower of Babel in Fritz Lang's Metropolis.

In the Theses on the Philosophy of History, Walter Benjamin suggests that all cultural treasures "owe their existence not only to the efforts of the great minds and talents who have created them, but also to the anonymous toil of their contemporaries. There is no document of civilization which is not at the same time a document of barbarism" (Benjamin, 1968, p. 256). The most obvious and prominent instances of cultural treasures in Benjamin's discourse can be found in monumental architectural works. History has shown that governments have been interested in these splendid stone statements, because these statements create a high status for rulers to stand upon.

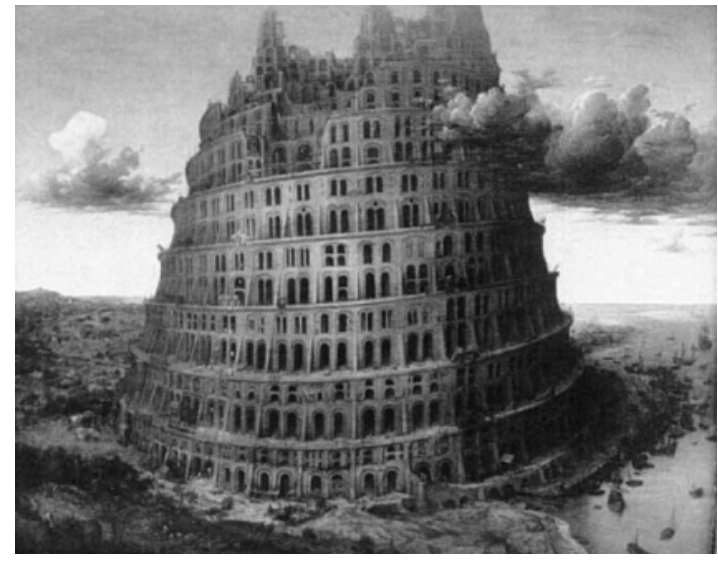

Figure 5. Tower of Babel as a symbol of union \& dispersion, construction \& destruction concepts (Painting of Tower of Babel by Peter Bruegel) (Source: Bonn, 2006, p. 134).

Before Benjamin, another great German philosopher, Friedrich Wilhelm Nietzsche, had mocked this grave-digging tendency to praising great historical works and their interpretation in line with progress and development: "There is a degree of insomnia, of rumination on the concept of history that harms any living creature, be it human or a group of humans, or a culture" (Nietzsche, $1980 / 2012$, p. 17). Benjamin (as cited by Richter, 2002) suggests that there is some constant dia$\log$ between construction and destruction and each construction keeps a type of destruction inside itself by default (Figure 5). From Benjamin's discourse, it is inferred that each work, not only potentially but also de facto, represents construction and destruction, civilization and barbarism, progress and disaster. 
Rumination on these great historical works gives a sense of fear, fear of a disaster that is on the other side of these manifestations of civilization and culture. Benjamin describes the angel of history: "Her eyes are wide open, her mouth is gaping, her wings are spread out. The angel of history must possess similar traits: where we see a chain of events she sees total catastrophe, an accumulation of debris upon debris" (as cited in Ahmadi, 2011, p. 1). It has been heard a lot that during construction of many big and monumental architectural works, which later shaped the biggest cultural documents of civilizations, individuals and workers who died over the course of building and finishing the work were buried among building materials. Benjamin asks: "With whom does historicism actually sympathize? The answer is inevitable: with the victor. And all rulers are the heirs of prior conquerors" (as cited in Ahmadi, 2011, p. 97). Benjamin's discourse challenges the conquering interpretation that defines the history as a forward advancing process. That is because each progress is accompanied with a disaster, and "the crumbling of the monuments that were built to signify the immortality of civilization becomes proof, rather, of its transiency" (BuckMorss, 1991, p. 170) (Figure 6).
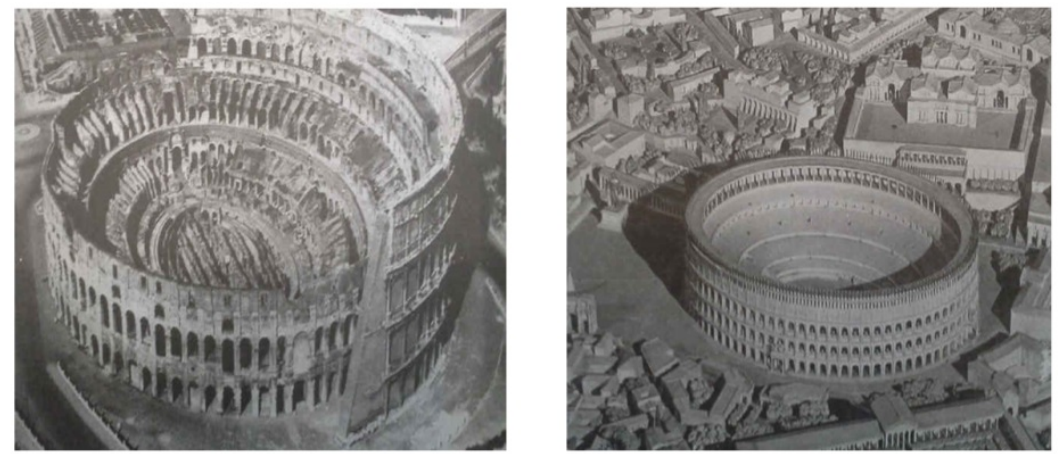

Figure 6 - Collapse, decadence $\&$ destruction of great cultural records (Source: Banimasoud, 2009, pp. 90, 91).

\section{Montage and History: Imaginary Territory of Cultural Geography}

The necessity of considering a difference between historical backgrounds of construction and formation of the artistic work with its present conditions is a point that Tzvetan Todorov (2010) correctly addresses in connection with Benjamin's text. Todorov emphasizes that historical conditions of production and creation of a work don't explain the meaning of the artistic work, and the work in each period can associate with meanings unlike what their creators intended to convey. However, it cannot be ignored that scope of perusal is intensely controlled by dominant ideology ${ }^{1}$ and as Benjamin (1968) puts it, culture transforms into a tool in the hands of the governing ideology. It could be suggested that each government, by shaping specific controlled methods of perusal through its power mechanisms, uses this cultural past with the purpose of consolidating and endorsing its power. Using intense suppression of opposite readings and marginalizing and devaluing artistic works different from dominant paradigms, the governing culture suppresses movements that oppose formation of cultural unity and disrupt integration of cultural geography (Bruno, 1993). To shape a comprehensive and consistent system, from among many works developed over historical periods, just a limited part is proposed in which desired cultural identity can be shaped and projected to the community via an apparatus. In his discourse on aura, Benjamin states that the concept of aura represents an ideological structure that can be developed as a result

\footnotetext{
${ }^{1}$ From Althusserian point of view, "Ideology makes a set of dialogs, pictures and concepts through which we realize our relationship with historical reality of life"( Ferretter, 2006/2008, p. 108)
} 
of processes and phenomena other than origin of the artwork (as cited by Emadian, 2012). For instance, regarding artworks and architecture, by projecting auras along the governing ideology on works, it becomes impossible to extract any other reading. This view seeks to propose a utopic image of artwork and architecture which, by consolidating this image, can represent these works as manifestations of civilization and national cultural identity, thus forming its desired "cultural geography territory". The aura that dominant ideology scattered over the artworks results in development of an environment in which every audience is affected by the preformed aura and doesn't even allow itself to get another perusal. Inspired from the discourse of Edward Said (2007), this comprehensive system can be considered as constructing an imaginary geography in the minds of a society's people. Based on Edward Said's orientalist discourse, what the West is presenting from the East is just a structure that consists of contexts drawn by orientalist explorers and scientists. In fact, what they call the East is a set of pictures and projections that together describe the nature of these geographic regions, geography that never existed in the real world. What an individual understands from east and eastern is, in fact, the product of this "imaginary geography". Resistance, durability, and integration of this "imaginary geography" is closely interrelated with maintaining the aura reflected on to these artistic works.

In the Arcades Project, Benjamin (1999) proposes adoption of a different methodological approach to history based on the montage logic and considers his writing style as literary montage that, instead of saying and stating, tries to represent: "Method of this project: literary montage. I needn't say anything. Merely show" (p. 460). Assemblage and adjacency of different discrete images results in a style of historical narration that can be accompanied with critical and political aspects. Opposing history writing in the form of progress, expansion, and manifestation, Benjamin rethinks the narrative, spatial, and temporal structure based on the process of montage. He looks at past conventional styles of history writing which, while apparently attempt to state the truth, in fact serve to hide power relations and endorse the hegemonic power. Suggesting "refuse of history", Benjamin (1999, p. 461) tracks marginalized, forgotten, and suppressed subjects in traditional historical reports, and with this approach he challenges the views of historians who consider their writings as history as it has happened. Benjamin, who introduced montage as his most important innovative methodology, emphasizes that this montage method connects together layers and fragments in various routes, disjoining them at the same time and avoiding any kind of end and completion (Scholem, \& Adorno, 1994). This understanding of montage resembling a rhizomatic connection is based on a nonlinear and anti-narrative understanding that is shaped from disjoints and inconsistencies and considers a historical narration as an organized totality of fragments and events that can be made in other different ways as well: "The first stage in this undertaking will be to carry over the principle of montage into history. That is, to assemble largescale constructions out of the smallest and most precisely cut components" (Benjamin, 1999, p. 460). Using montage in facing these cultural-historical documents, a movement to broader horizons for reading of these works can be started. Discovery, reinterpretation, and attempt to put silent and ignored works alongside those splendor works, or reviewing those splendid proofs, free from ideological views can result in disintegration of the comprehensive system. As a result, with decadence of this comprehensive system and removal of ideological auras besprinkled by hegemonic power, "the cultural imaginary geography" also turns into fragmented and discrete parts.

\section{Cinema, Architecture, and Informing: Montage and the Pleasure of Fragmenting Splendid Works}

The de-constructivist contemporary architect, Bernard Tschumi (1997), seeks in his works to destabilize and destruct the traditional role of architecture as an art with the purpose of consolidating the political power of the government. The important point according to Tschumi is creation and establishment of an architecture that serves against "architecture" (in its traditional sense of 
the word): "Architecture only survives where it negates the form that society expects of it. Where it negates itself by transgressing the limits that history has set for it" (p. 106). Tschumi believes that this is possible only via interaction of architecture with other areas and use and inspiration of capacities in other areas. Thus, he addresses the similarity of film and architecture: "Film analogies [to architecture] are convenient, since the world of cinema was the first to introduce discontinuity - a segmented world in which each fragment maintains its own independence, thereby permitting a multiplicity of combinations" (Tschumi, 1996, p. 196). Inspired by the views of Benjamin and Eisenstein, he considers shock in architecture as a dramatic tool to parallel architecture with montage and film and tries to shape an anti-centric and off-historic structure in architecture.

Tschumi emphasizes that in cinema, space is understood in interaction with the human body and sense and such a look has to be stressed in architectural discourse. Influenced by the theory of montage in USSR's cinema, and especially Eisenstein's thought, he adds two concepts of event and movement to the concept of architectural space, arguing that meaning of any architectural status depends on produced sequence based on the triple relation of space, event, and movement. He believes that, as in cinema the relationship between frames and sequences can be manipulated using techniques such as flashback, jump cut, and dissolve, providing arbitrary adjacencies, architectural spaces and forms also, like filmic frames, can together be superimposed, cut, dissolved, and faded, providing countless facilities for formation of architectural sequences. In Figure 7 we can see that the ambiance and elements of the scene of both parts are the replica of each other, however the movement and changes of position of elements causes the picture to change. This proves that movement and change in position could create different pictures and space. Therefore, it provides the potential alternative opportunity for more architectural space and pictures.
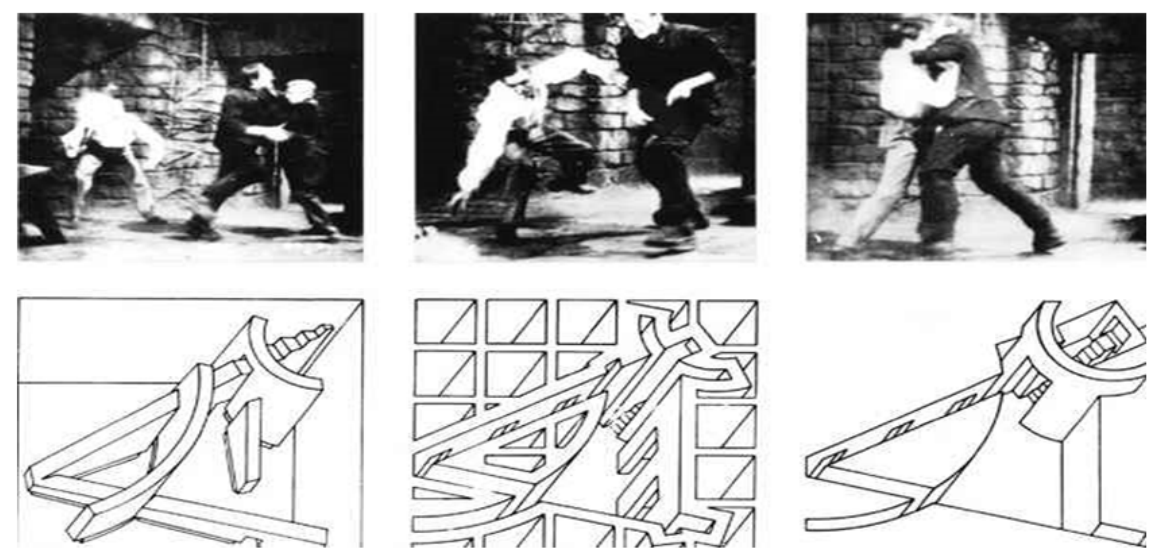

Figure 7. Tschumi's attempts in employing the formal and narrative inventions of cinema to enrich the time-space nature of contemporary architecture.

(Source: Damiani, 2003/2007, p. 29).

Tschumi's interest in challenging stability and durability of architecture stands against the traditional views of architecture that are coupled with concepts like resistance, stability, and structure. Referring to Deleuze's discourse (as cited on Tschumi, 1996) regarding the productive role of cinematic concepts, he argues that film can open new horizons in understanding and creating architectural spaces, and film theory has to be used as an instrument to expand and motivate the theory of architecture. The concept of disjunction proposed by Tschumi is an attempt to destruct architecture's traditional sense and to relate it with fragmented postmodern culture. In this regard, disjunction stands opposite to historical attempts of architecture that always tried to consolidate unity, harmony, and balance. Tschumi believes that his architecture can be considered as something "to encourage conflict over synthesis, fragmentation over unity, madness and play over careful management." (Tschumi, 2003, p. 451). 
Every bit and every space in cinematic atmosphere could transform easily to another bit and space and destroy hierarchy by cinematic techniques free of any limitation. According to Tschumi in order for architecture to survive it has to follow the cinema. Keywords by Tschumi are the following: fragmented, unstability, unstructured, compliance, and insanity.

Tschumi in Park de la Villette utilized fragmentation, unstability, and insanity in combination to create phenomenal landmarks. He created a structural plan for the entire park which was very unconventional. He put the elements together in insane way which wasn't even functional (Figure 8). When you take a stroll through the park your eyes become mesmerized by red elements which seem to be standing out on their own without any discipline or organization. Every minute leaves you in awe and is unpredictable. Just the way Tschumi has stated in his theories architecture can only be alive when the form that society is expecting will be disavowed.

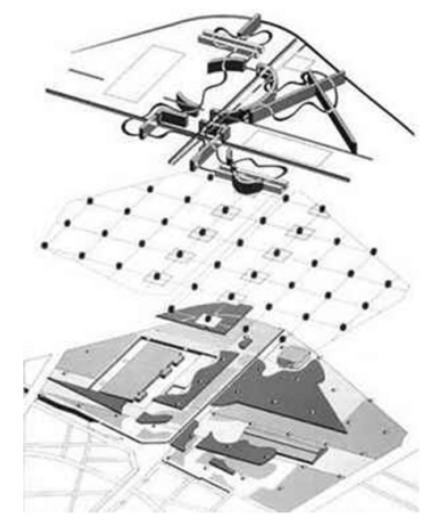

Figure 8 - Tschumi's disjunctive and fragmented design in his project 3D model, park de la villette in paris,France, is indebted to montage technique, and specially influenced by Eisenstein's thoughts.

(Damiani, 2003/2007, 29).

Referring to the famous sentence by Orson Welles, great director of US cinema, he had said, "I don't like architecture, I like making architecture" (Tschumi, 2003, p. 445). Tschumi also writes, "my own pleasure has never surfaced in looking at buildings, at the great works of the history or the present of architecture, but. Rather, in dismantling them" (Tschumi, 2003, p. 445). This type of architecture, based on cinematic montage, can be considered as an effort to fragment and disjoin imaginary geography based on unity and disintegration.

\section{Conclusion}

Gilles Deleuze believed that perusal of artistic works should not be a study in their history and de velopmental background; this perusal must allow us to once again face formation of idea. He also considered freedom in reading and interpretation, free from historical limitations as a background for development of new creations in terms of theory. Through the rhizomatic nature of cinematic images, each point and space can connect to other points and spaces free from any limitation and, thus, the audience's idea is constantly stimulated to establish relative fluid relations between imag es and concepts. Reminding the audience of the limitations of traditional history writing and provi ding new routes of thinking and looking at history, cinematic thinking can challenge dominant his torical narratives, changing our feeling and understanding of what has happened in the past and $\mathrm{w}$ hat exists at present, because each status only finds meaning in its relationship with the past.

Using montage thinking in the face of splendid cultural treasures, such as architectural monuments, other varieties of thinking regarding these works can be experienced. This type of thinking and re view, despite its historic past and cultural symbols and manifests, can result in a deterritorializatio 
$\mathrm{n}$ of territories dealing with concepts such as civilization/barbarism, culture/savagery. This style o f "cinematic thinking" serves as an effort to open territories of theory of art and architecture using ideas that dynamic cinematic images leave in the mind. As shown in the essay, using this disting uished type of thinking offers an opportunity for unexpected ruptures and explosions in the area o $\mathrm{f}$ theorizing, and can, as an environment for creation, provide many possibilities and capacities in relation with creation of theory of art and architecture. And it is our hope that montage thinking $\mathrm{m}$ ay also positively impact the theory of informing.

\section{References}

Ahmadi, B. (2011). Memoirs of darkness, on three thinkers of the Frankfurt School. Tehran: Markaz Publishers.

Andrew, D. (2010). The major film theories: An introduction. (M. Madani, Trans.). Tehran: Rahrovan Poyesh Pub. (Original work published 1976)

Banimasoud, A. (2009). A history of western architecture: From ancient to School Chicago. Isfahan: Khak Pub.

Benjamin, W. (1968). Illuminations (Vol. 241, No. 2). Schocken Books Incorporated.

Benjamin, W. (1999). The Arcades Project. (R. Tiedemann, Ed.; H. Eiland \& K. McLaughlin, Trans.). Harvard University Press.

Benjamin, W. (2011). The work of art in the age of mechanical reproduction. In The screening of thought: Episodes of film philosophy (P. Yazdanjoo, Trans.), Tehran: Markaz Pub. (Original work published 1936)

Bonn, R. L. (2006). Painting life: The art of Pieter Bruegel, the Elder. Chaucer Press Books.

Bruno, G. (1993). Streetwalking on a ruined map: Cultural theory and the city films of Elvira Notari. Princeton: Princeton University Press.

Buck-Morss, S. (1991). The dialectics of seeing: Walter Benjamin and the Arcades Project. MIT Press.

Damiani, G. (2007). Bernard Tschumi. (M. Ebrahimabadi, Trans.). Ganje Honar publication. (Original work published 2003)

Deleuze, G. (2005). Cinema II. Bloomsbury Academic.

Denzin, N. K., \& Lincoln, Y. S. (2011).The SAGE handbook of qualitative research. Sage Publications.

Eisenstein, S. (1991). Selected works: Towards a theory of montage (Vol. 2). British Film Institute.

Emadian, B. (2012). Natural history of decadence (thoughts on a destroyed subject). Tehran: Bidgol Pub.

Emberley, J. (2002). Body, interrupted: Textual montage, traumatized bodies, and the de-disciplining of knowledge. Resources for Feminist Research, 29(3-4), 69-84.

Ferretter, L. (2008). Louis Althusser (A. Ahmadi Aryan, Trans.), Tehran: Markaz Publication. (Original work published 2006)

Jaskot, P. B. (2002). The architecture of oppression: The SS, forced labor and the Nazi monumental building economy. Routledge.

Khorsandi Tasko, A. (2008). Knowledge's Interdisciplinary discourse: Typology, theoretical principles and policies for practice in higher education. Cultural and Social Studies Research, Tehran.

Khorshidi, G. H., \& Pishgahi, S. (2012). Capacities and Obstacles for Developing Interdisciplinary Humanities. Journal of Interdisciplinary Studies in the Humanities, 2, 1-15.

Koepnick, L. P. (1999). Walter Benjamin and the aesthetics of power. University of Nebraska Press.

Lampugnani, V. M. (2011). Architecture and city planning in the twentieth century (L. Etezadi \& S. Beheshti, Trans.). Tehran: University Press. (Original work published 1985) 
Lang, F., Von Harbou, T., Abel, A., Fröhlich, G., Helm, B., Huppertz, G., \& Universität der Künste Berlin. (1989). Metropolis. Faber \& Faber.

Marcus, G. E. (1995). The modernist sensibility in recent ethnographic writing and the cinematic metaphor of montage. In Fields of vision: Essays in film studies, visual anthropology, and photography. (L. Devereaux \& R. Hillman Eds.), University of California Press.

Nesbet, A. (2003). Savage junctures: Sergei Eisenstein and the shape of thinking. London \& New York: I.B.Tauris.

Nietzsche, F. (2012). On the advantage and disadvantage of history for life, (A. Kashef \& A. Sohrab, Trans.). Tehran: Forozan Rouz Pub. (Original work published 1980)

Phillips, J. (2008). Cinematic thinking: Philosophical approaches to the new cinema. Stanford, CA, USA: Stanford University Press.

Repko, A. F., Newell, W. H., \& Szostak, R. (2011). Case studies in interdisciplinary research. SAGE Publication

Richter, G. (2002). Benjamin's ghosts: Interventions in contemporary literary and cultural theory. Stanford University Press.

Said, E. (2007). Orientalism (A. Govahi, Trans.). Tehran: Bureau of Islamic Culture Publication.

Scholem, G., \& Adorno, T. W. (Eds.). (1994). the correspondence of Walter Benjamin, 1910-1940 (M, R. Jacobson \& E. M. Jacobson, Trans.). Chicago, USA: University of Chicago Press.

Sontag, S. (2002). Under the sign of Saturn: Essays. London: Picador.

Stam, R. (2010). Film Theory: An Introduction (translators group under E. Nowroozi, Trans.). Tehran: Soureh Mehr Pub. (Original work published 2000)

Tawa, M. (2010). Agencies of the frame: Tectonic strategies in cinema and architecture. Newcastle: Cambridge Scholars Publishing.

Taylor, R. R. ( 1974 ). The word in stone: The role of architecture in the national socialist ideology. University of California Press.

Todorov, T. (2010). The Fear of Barbarians: Beyond the Clash of Civilizations (A. Brown, Trans.). University of Chicago Press.

Tschumi, B. (1996). Architecture and disjunction. MIT press.

Tschumi, B. (1997). Bernard Tschumi: Architecture in/of motion. Distributed Art Pub Inc.

Tschumi, B. (2003). Parc de la Villette, Paris. In J. D. Culler (Ed.), The Deconstruction: Critical concepts in literary and cultural studies (Vol. 3). Psychology Press.

\section{Biographies}

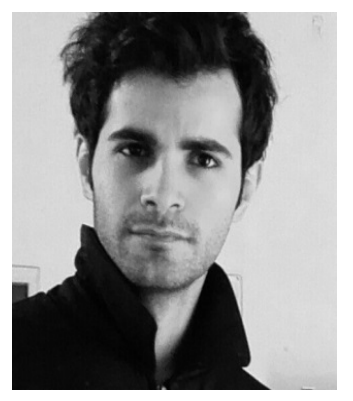

Emad Moaddab is a M.A student of architectural engineering at the University of Kamalolmolk. His research interests include art theory, cinematic architectural, and art history. He is author of five research publications. 